\title{
TURBINE GENERATOR EFFICIENCY ANALYSIS IN GEOTHERMAL POWER PLANT PT GEODIPA ENERGI UNIT DIENG
}

\author{
Alfian Hardi Qurrahman ${ }^{1 *}$, Wahyu Wilopo ${ }^{2)}$, Himawan Tri Bayu ${ }^{3)}$ \\ *Master Of Systems Engineering, Universitas Gadjah Mada, Indonesia \\ Jl. Teknika Utara, No.3, Barek, Kocoran, Caturtunggal, Kec. Depok, Kabupaten Sleman, \\ Daerah Istimewa Yogyakarta 55281 \\ E-mail: 1alfian.hardiq@gmail.com
}

\begin{abstract}
The Geothermal power plant at PT Geodipa Dieng has been operating for more than 10 years. It has undergone for several improvements including the replacement of turbines where to increase turbine efficiency. Before changing the turbine, the efficiency of turbine has decreased due to several factors, such as decrease in load, maintenance, usage, the lifetime etc. Therefore it needs to be analyzed the effiency of the turbine to find out whether the turbine is still feasible or not, and to find out whether it has necessary to replace the turbine again. The result of the turbine generator efficiency are obtained in one year from April 2017 to March 2018 with an average value of 70-85\%. Based on the literature, the value is still at the turbine efficiency standard in general, which is 60-80\%. So the turbines can still be categorized reliably and do not need to be changed.
\end{abstract}

Keywords: Geothermal, Efficiency turbine, Geodipa Dieng

\section{Pendahuluan}

Energi fosil masih menjadi pilihan utama di berbagai negara di dunia di dalam hal pembangkit tenaga listrik. Negara-negara tersebut tidak sedikit pula yang melakukan persaingan untuk mendapatkan energi fosil tersebut. namum semakin berjalannya waktu energi fosil semakin ditinggalkan karena adanya energi terbarukan, salah satunya adalah energi panas bumi. Energi panas bumi merupakan alternatif yang sedang diminati oleh negara-negara di dunia untuk menggantikan energi fosil di dalam hal pembangkit tenaga listrik. Ada beberapa di dunia yang telah memanfaatkan energi panas bumi yaitu Prancis, Italy, Inggris, Jepang, dan bahkan Indonesia

Indonesia merupakan negara yang mempunyai energi panas bumi terbesardi dunia yaitu sebesar $40 \%$ dari cadangan panas bumi yang ada di dunia. Panas bumi di Indonesia tersebar di sepanjang jalur lempeng tektonik, mengikuti cincin gunung api. Terhitung sebanyak 312 titik potensi panas bumi yang tersebar di sepanjang pulau Sumatera, Jawa, bali, Nusa tenggara, Sulawesi Utara dan maluku utara dengan potensi mencapai $28.910 \mathrm{MW}$ dengan total cadangan $16.524 \mathrm{Mw}$ dan kapasitas terpasang masih mencapai 1.403 Mw (MEMR, 2015).

Panas bumi yang terpasang harus terus ditingkatkna dan untuk yang telah terpasang harus terus dijaga agar tidak terjadi pengurangan daya yang terpasang, hal ini dapat dilakukan dengan terus melakukan monitoring dan pemeilharaan dari semua komponen pembangkit listrik tenaga panas bumi tersebut, salah satu komponen yang paling penting untuk terus dilakukan pemeliharaan adalah turbin generator. Turbin generator merupakan komponen yang menghasilkan listrik, komponen tersebut mengkonversi energi panas dari sumber panas bumi menjadi energi listrik.

Konversi energi panas ke energi listrik akan semakin baik ketika efisiensi turbin tersebut semakin baik, efisiensi turbin penting untuk diperhatikan dan terus dimonitoring karena 
ketika efisiensi turbin kecil maka aliran massa yang masuk turbin akan semakin besar. Oleh karena itu efisiensi turbin harus terus dalam keadaan handal agar aliran massa yang masuk turbin tidak besar, dan agar daya yang dihasilkan dari aliran massa yang tidak terlalu besar tersebut maksimal. Saat turbin sudah tidak handal maka perlu dilakukan pearwatan bahkan perlu dilakukan pergantian termasuk pergantian turbin yang dilakukan oleh PT Geodipa Dieng, untuk meningkatkan daya yang dihasilkan perlu dilakukan pergantian turbin. Pada tahun 2014 daya yang dihasilkan generator sebesar 21,71 Mw (Agung, Itoi, Jalilinasrabady, \& Jaelani, 2014), pada tahun 2018 daya yang dihasilkan dapat meningkat kerena adanya pergantian turbin yang dilakukan PT tersebut.

\section{Metodelogi penelitian}

\subsection{Dasar Teori}

\subsubsection{Mass Balance}

Di dalam suatu sistem tertutup massa dari suatu aliran dianggap konstan sehingga diberikan oleh persamaan berikut (Loh, 1968).

$$
\frac{d}{d t} \int_{V} p d V=0
$$

Dimana $V$ adalah volume dan $p$ adalah kerapatan massa.

\subsubsection{Energy Balance}

Pada pertengahan abat 19 ditemukan sebuah fakta bahwa energi kinetik dan energi potensial dapat diubah menjadi energi panas tanpa merubah nilai dari kedua energi tersebut, penemuan tersebut sampai saat ini terkenal dengan sebutan hukum termodinamika pertama yaitu "Jumlah kalor pada suatu sistem ialah sama dengan perubahan energi di dalam sistem tersebut ditambah dengan usaha yang dilakukan oleh sistem" (Loh, 1968)

\subsubsection{Efisiensi Generator}

Efisiensi panas dari sistem pembangkit listrik didefinisikan sebagai rasio daya keluaran bersih dan panas yang dilepaskan dari sumber energi panas bumi, yang didefinisikan sebagai persamaan berikut (Yao, Zhang, \& Yu, 2018)

$$
\eta_{\text {system }}=\frac{\dot{W}_{\text {net }}}{\dot{Q}_{w}}
$$

$\dot{W}_{n e t}$ dan $\dot{Q}_{w}$ dapat ditulis dengan persamaan berikut ini

$$
\begin{gathered}
\dot{Q}_{w}=\dot{m}_{w}\left(h_{w 1}-h_{w 2}\right) \\
\dot{W}_{n e t}=\sum \dot{W}_{E}-\dot{W}_{P}
\end{gathered}
$$

Dimana:

$\eta_{\text {system }}=$ efisiensi panas dari sistem

$\dot{W}_{\text {net }}=$ Daya keluaran bersih $(\mathrm{kW})$

$\dot{Q}_{w}=$ Aliran panas dari geothermal water

$\dot{W}_{E}=$ Daya keluaran expander $(\mathrm{kW})$

$\dot{W}_{P}=$ Daya keluaran pump $(\mathrm{kW})$

$\dot{m}_{w}=$ laju aliran massa $(\mathrm{kg} / \mathrm{s})$ 
$h_{w 1}=$ entalpi spesifik dari geothermal water $1(\mathrm{Kj} / \mathrm{kg})$

$h_{w 2}=$ entalpi spesifik dari geothermal water $2(\mathrm{Kj} / \mathrm{kg})$

\subsection{Pengumpulan data}

Data yang dikupulkan berupa data primer dan data sekunder. Data primer di dapatkan melalui pengukuran langsung di PT Geodipa Dieng yang berupa data suhu dan tekanan pada tuerbin milik pembangkit listrik tenaga panas bumi (PLTP) milik PT Geodipa Dieng.

Data sekunder dikumpulkan dari sumber-sumber data yang dianggap relevan dengan penelitian ini yaitu berupa paper-paper dan data literature terdahulu.

\subsection{Pemprosesan data}

Pengolahan parameter suhu dan tekanan dengan cara interpolasi menggunakan steam table untuk mendapatkan nilai volume spesifik, energi dalam, entalpi dan entropi pada setiap komponen turbin milik PT Geodipa Dieng

Pengolahan data flow rate dan entalpi pada turbin generator untuk mendapatkan nilai efisiensi dari turbin generator. Seteleh mendapatkan nilai efisiensi turbin maka dianalisis apakah nilai tersebut masih sesuai dengan refrensi atau literatur yang didapatkan pada pengumpulan data sekunder. Dari nilai efisiensi tersebut dapat dilihat juga apakah turbin tersebut masih handal atau tidak sesuai refrensi

\section{Hasil \& Pembahasan}

\subsection{Data Penelitian}

Data yag diambil berupa data suhu dan tekanan pada turbin dalam waktu satu tahun, Tabel 1 merupakan beberapa data suhu dan tekanan pada turbin PT Geodipa Dieng baik input maupun Output.

Data tersebut selanjutnya diolah untuk didapatkan nilai entalpi, entropi dll, yang selanjutnya bersama dengan flowrate nilai entalpi dan entropo akan digunakan untuk mencari nilai efisiensi turbin.

Tabel 1. Data Penelitian

\begin{tabular}{|c|c|c|c|c|c|c|}
\hline \multirow{2}{*}{$N 0$} & \multirow{2}{*}{ Date } & \multirow{2}{*}{$\begin{array}{c}\text { flow } \\
\text { rate }\end{array}$} & \multicolumn{4}{|c|}{ Turbin } \\
\cline { 4 - 7 } & & & \multicolumn{2}{|c|}{ input } & \multicolumn{2}{c|}{ Output } \\
\cline { 4 - 7 } & & Suhu & Tekanar & Suhu & Tekanan \\
\hline \multicolumn{2}{|c|}{ Satuan } & ton/hr & C & bar & C & bar \\
\hline 1 & $31 / 03 / 2018$ & 328 & 155 & 8,2 & 42,7 & $-0,52$ \\
\hline 2 & $29 / 03 / 2018$ & 358 & 152 & 8,4 & 42,6 & $-0,51$ \\
\hline 3 & $02 / 02 / 2018$ & 331 & 150 & 8,6 & 42 & $-0,61$ \\
\hline 4 & $02 / 01 / 2018$ & 352 & 152 & 8,3 & 42,4 & $-0,55$ \\
\hline 5 & $01 / 01 / 2018$ & 349 & 143 & 8,4 & 41,6 & $-0,58$ \\
\hline 6 & $02 / 12 / 2017$ & 364 & 142 & 8,4 & 42,6 & $-0,6$ \\
\hline 7 & $01 / 12 / 2017$ & 358 & 140 & 8,3 & 42,3 & $-0,61$ \\
\hline 8 & $02 / 11 / 2017$ & 337 & 142 & 8,4 & 41,3 & $-0,56$ \\
\hline 9 & $01 / 11 / 2017$ & 330 & 144 & 8,2 & 40,3 & $-0,62$ \\
\hline 10 & $02 / 10 / 2017$ & 278 & 151 & 8,4 & 40,4 & $-0,64$ \\
\hline 11 & $01 / 10 / 2017$ & 256 & 140 & 8,5 & 39,7 & $-0,66$ \\
\hline 12 & $02 / 09 / 2017$ & 329 & 152 & 8,5 & 40,9 & $-0,62$ \\
\hline 13 & $01 / 09 / 2017$ & 313 & 151 & 8,5 & 40,6 & $-0,61$ \\
\hline 14 & $04 / 08 / 2017$ & 330 & 151 & 8,4 & 43,1 & $-0,56$ \\
\hline 15 & $03 / 08 / 2017$ & 320 & 139 & 8 & 42,1 & $-0,57$ \\
\hline 16 & $02 / 07 / 2017$ & 311 & 139 & 8,2 & 41,8 & $-0,61$ \\
\hline 17 & $01 / 07 / 2017$ & 314 & 132 & 8,4 & 41 & $-0,61$ \\
\hline 18 & $02 / 06 / 2017$ & 324 & 125 & 8,3 & 43 & $-0,64$ \\
\hline 19 & $01 / 06 / 2017$ & 321 & 124 & 8,3 & 43,2 & $-0,63$ \\
\hline 20 & $02 / 05 / 2017$ & 344 & 134 & 8,3 & 41,8 & $-0,59$ \\
\hline 21 & $01 / 05 / 2017$ & 335 & 137 & 8,4 & 42,4 & $-0,6$ \\
\hline 22 & $02 / 04 / 2017$ & 283 & 132 & 8,3 & 40,3 & $-0,64$ \\
\hline 23 & $01 / 04 / 2017$ & 301 & 138 & 8,4 & 41 & $-0,65$ \\
\hline & & & & & & \\
\hline
\end{tabular}




\subsection{Perhitungan Mass Balance}

Berikut ini adalah contoh pengolahan neraca massa pada turbin. Perhitungan ini dilakukan untuk melihat bahwa tidak ada massa yang hilang saat proses turbin berlangsung atau bekerja sehingga efisiensi pada turbin benar-benar berasal dari aliran massa yang masuk dan yang keluar turbin

Dengan asumsi fluida masuk turbin adalah steam dan keluaran turbin terdiri dari steam dan konensat, maka didapat:

Laju alir steam masuk turbin $=$

Steam keluaran turbin $\quad=$ 341,725 ton/jam

Kondemsat keluaran turbin $=$ Total laju alir keluaran turbin $=$

$$
\begin{aligned}
& 0,7949 \times 341,725 \text { ton/jam }=271,631 \mathrm{ton} / \mathrm{jam} \\
& 0,2051 \times 341,725 \text { ton/jam }=70,094 \text { ton/jam } \\
& 341,725 \text { ton/jam }
\end{aligned}
$$

Tabel 2. Neraca Massa di Turbin

\begin{tabular}{|c|c|c|}
\hline \multirow{2}{*}{ Komponen } & $\begin{array}{c}\text { Input } \\
\text { (ton/h) }\end{array}$ & $\begin{array}{c}\text { Output } \\
\text { (ton/h) }\end{array}$ \\
\cline { 2 - 3 } & $\mathrm{F} 1$ & $\mathrm{~F} 2$ \\
\hline Uap & 341,725 & 271,631 \\
\hline Air & - & 70,094 \\
\hline Jumlah & 341,725 & 341,725 \\
\hline
\end{tabular}

Adapun neraca massa dengan perhitungan data dalam waktu satu tahun yaitu seperti pada Gambar 1.

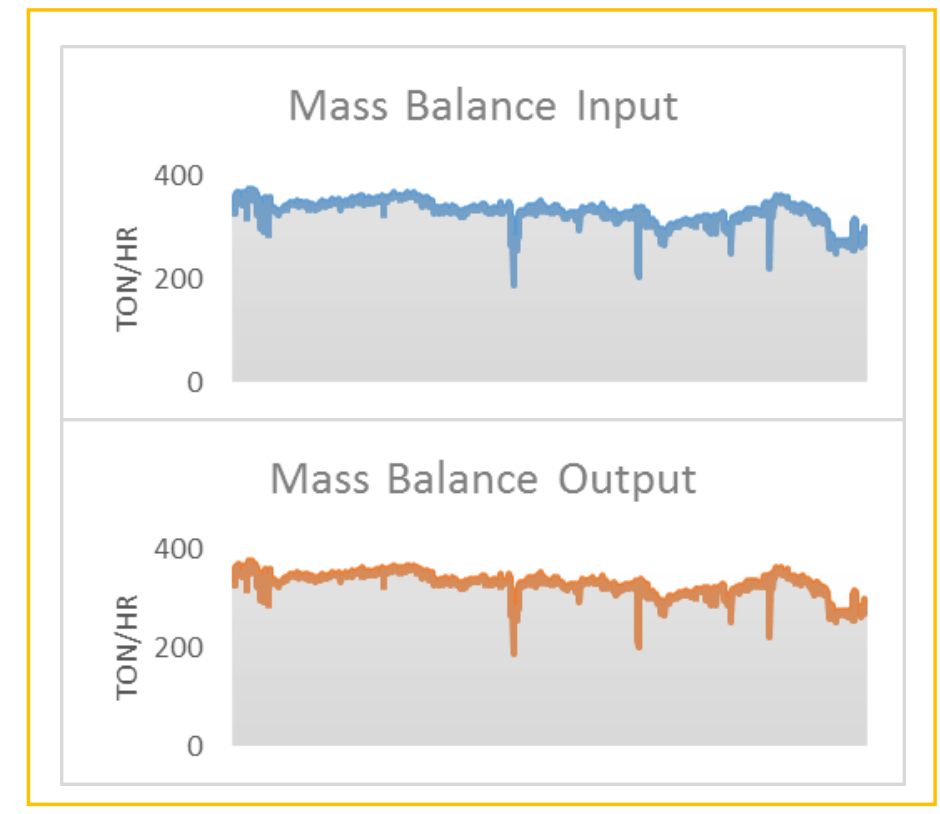

Gambar 1. Neraca massa

Nilai mass balance yang yang diperoleh merupakan nilai mass balance yang terjadi di dalam turbin, nilai tersebut dipengaruhi oleh flowrate dari fluida dan kandungan fraksi uap pada turbin, dengan asumsi fluida yang masuk turbin berupa steam dan yang keluar turbin berupa stem dan kondensat. 


\subsection{Perhitungan Neraca energi}

Energi balance yang ditinjau berupa energi panas yang masuk pada turbin dimana energi panas tersebut didapatkan dari perbandingan panas yang masuk dan panas yang keluar turbin. Panas yang masuk berupa steam yang dihitung dengan mengalikan flowrate dan nilai entalpi panas dalam wujud uap. Panas yang keluar turbin berupa steam dan kondensat yang dihitung dengan menjumlahkan beberapa panas yaitu panas dari air, panas dari uap, panas laten dan panas yang terpakai (panas mekanik). Tabel 3 menunjukkan salah satu contoh perhitungan neraca panas pada tanggal 31 maret 2018.

Tabel 3. Neraca Panas di Turbin

\begin{tabular}{|c|c|c|}
\hline \multirow{2}{*}{ Komponen } & In $(\mathrm{kJ} / \mathrm{s})$ & Out $(\mathrm{kJ} / \mathrm{s})$ \\
\cline { 2 - 3 } & Q1 & Q2 \\
\hline Air & - & 785,998 \\
\hline Uap & 250774,222 & 3437,39 \\
\hline Panas Laten & - & 59570,3 \\
\hline Panas Energi & - & 186980,571 \\
\hline Jumlah & 250774,222 & 250774,222 \\
\hline
\end{tabular}

Gambar 2. menunjukkan nilai neraca panas pada PLTP Geodipa Energi unit dieng dalam waktu satu tahun dari april 2017 sampai maret 2018. Dengan mengetahui neraca panas kita dapat mengetahui bahwa tidak ada panas yang berasal dari lingkungan dan yang menuju lingkungan segingga efisiensi dari turbin tidak terpengaru oleh kehilangan panas karena lingkungan dan menuju lingkungan.

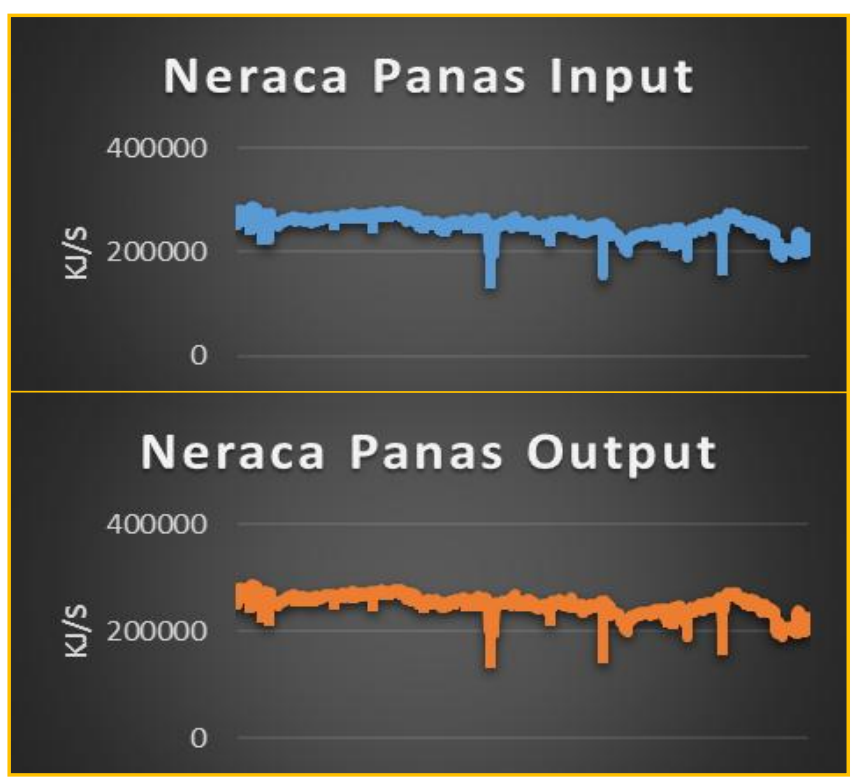

Gambar 2. Neraca Panas

\subsection{Perhitungan Efisiensi Turbin}

Proses yang berlangsung di dalam turbin adalah ekspansi isentropik sehingga entropi masuk turbin sama dengan entropi keluar turbin. Besarnya fraksi uap dan kondensat yang keluar turbin dapat dihitung berdasarkan data entropi cair (Sf) dan entropi gas ( $\mathrm{Sg}$ ) pada kondisi outlet turbin

Efisiensi turbin generator merupakan perbandingan antara daya kotor yang masuk turbin 
dan daya keluaran bersih dari generator, hal ini dikarenakan turbin dikopel dengan generator dan bekerja secara bersama-sama. Berikut ini merupakan salah satu contoh perhitungan efisiensi turbin. Tabel 4. menunjukkan hasil interpolasi dari Steam Table

Tabel 4. Data Saturated Steam Table pada Tekanan Outlet Turbin

\begin{tabular}{|c|c|c|c|c|}
\hline $\begin{array}{c}\text { Tekanan } \\
\text { (bar) }\end{array}$ & $\begin{array}{c}\mathrm{Hg} \\
(\mathrm{kJ} / \mathrm{kg})\end{array}$ & $\begin{array}{c}\mathrm{Hf} \\
(\mathrm{kJ} / \mathrm{kg})\end{array}$ & $\begin{array}{c}\mathrm{Sg} \\
(\mathrm{kJ} / \mathrm{kg} . \\
\mathrm{K})\end{array}$ & $\begin{array}{c}\mathrm{Sf} \\
(\mathrm{kJ} / \mathrm{kg} . \\
\mathrm{K})\end{array}$ \\
\hline & & & & \\
\hline 0,075 & 2573,9 & 168,74 & 8,2494 & 0,57625 \\
\hline 0,0988 & $\mathrm{Hg} 2$ & $\mathrm{Hf} 2$ & $\mathrm{Sg} 2$ & $\mathrm{Sf} 2$ \\
\hline 0,1 & 2583,8 & 191,83 & 8,1482 & 0,64926 \\
\hline
\end{tabular}

$$
\begin{array}{ll}
\eta \text { Turbin } & =\frac{\mathrm{Ws}}{\mathrm{W} \text { isentropik }} \\
& =\frac{46,075}{64,7459} \times 100 \% \\
& =71,16 \%
\end{array}
$$

Efisiensi menunjukkan seberapa besar daya yang mampu dikonversi oleh generator dari inputan energi yang ada. Besarnya efisiensi turbin-generator pada pembangkit listrik tenaga panas bumi PLTP Geodipa Energi Unit Dieng. Gambar 3 menunjukkan besarnya nilai efisiensi turbin-generator pada PLTP Dieng.

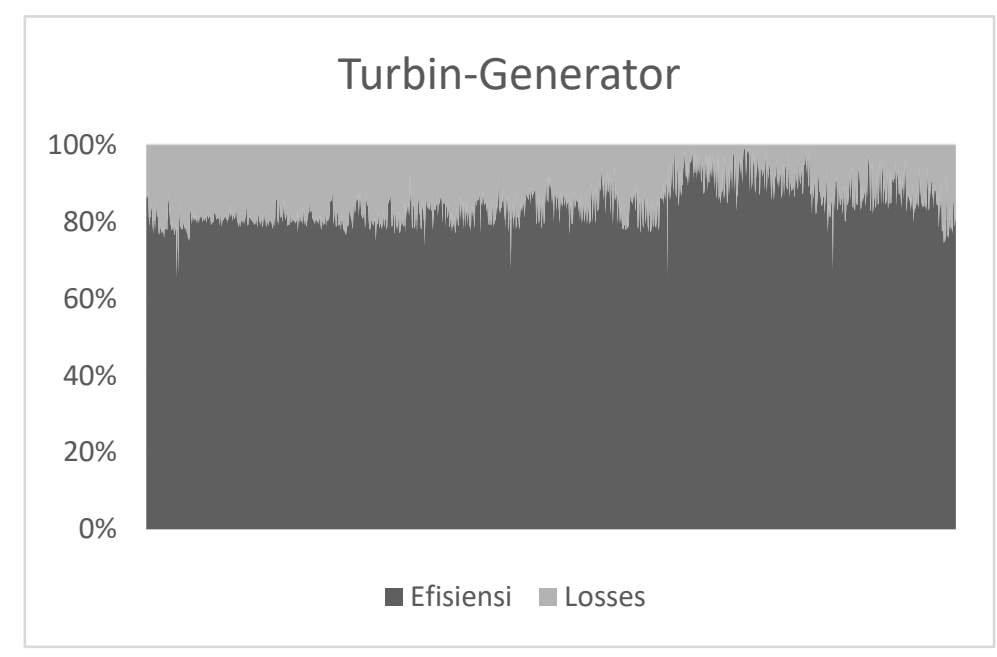

Gambar 3. Efisiensi Turbin Geodipa

Nilai efisiensi turbin-generator PLTP Dieng pada Gambar 3. rata-rata bernilai diatas $70 \%$ dan di bawah 85\%. Pada kondisi terendah efisiensi dari pembangkit tersebut masih berada di angka $60 \%$ hal ini masih sesuai dengan nilai efisiensi yang ditunjukkan oleh studi literatur yaitu sebesar 60-80\%. (Zarrouk \& Moon, 2014). Kondisi terendah pada sistem tersebut terjadi ketika flowrate yang masuk pada turbin nilainya sangat kecil, dan berada di bawah nilai yang seharunya dapat ditampung oleh suatu turbin. Nilai efisiensi yang melebihi $90 \%$ disebabakan oleh flowrate yang lebih besar dari yang seharusnya ditampung oleh turbin. Secara garis besar nilai efisiensi seharusnya tidak dipengaruhi oleh besarnya flowrate, besarnya flowrate yang masuk pada turbin hanya menunjukkan kemampuan turbin dalam menampung uap panas dari separator, semakin besar daya tampung turbin maka hasil yang 
diolah turbin menjadi daya akan semakin besar, begitupula sebaiknya

\section{Kesimpulan}

1. Nilai efisiensi turbin PLTP Geodipa Dieng masih sesuai dengan refrensi atau studi literature PLTP pada umumnya dengan nilai $70-85 \%$.

2. Efisiensi turbin PT Geodipa Dieng dapat dikatakan masih handal karena masih berada di atas nilai refrensi atau studi literatur yaitu $60-80 \%$

\section{Daftar Pustaka}

[1] Pambudi, N. A., Itoi, R., Jalilinasrabady, S., \& Jaelani, K. (2014). Exergy analysis and optimization of Dieng single-flash geothermal power plant. Energy Conversion and Management, 78, 405-411.

[2] Loh, W. H. T. (1968). Fundamentals of Thermodynamics and Aerothermodynamics. In Jet, Rocket, Nuclear, Ion and Electric Propulsion (pp. 3-116). Springer, Berlin, Heidelberg.

[3] Energi, K., \& Mineral, S. D. (2015). Rencana Strategis Kementerian ESDM Tahun 20152019.

[4] Yao, S., Zhang, Y., \& Yu, X. (2018). Thermo-economic analysis of a novel power generation system integrating a natural gas expansion plant with a geothermal ORC in Tianjin, China. Energy, 164, 602-614.

[5] Zarrouk, S. J., \& Moon, H. (2014). Efficiency of geothermal power plants: A worldwide review. Geothermics, 51, 142-153. 
Alfian Hardi Qurrahman, Wahyu Wilopo, Himawan Tri Bayu 